\title{
O VALOR MATERIAL E SIMBÓLCO DA RENDA RENASCENÇA
}

\author{
ELSE DE F. ALBUQUERQUE
}

Faculdade de Ciências Socia is Ap lic a das

MARILDA MENEZES

Universidade Federal de Campina Grande

\begin{abstract}
Resumo: 0 município de Camalaú, situado no Cariri paraibano, destaca-se pela fabricação da renda renascença. Em toda a região, essa a tivida de assume grande importância econômica que pode ser observada, dentre outros aspectos, na quantidade de mulheres que trabalham na confecção da renda; há cerca de qua tro mil mulheres que se dedicam simultaneamente à a gricultura familiar e a o artesanato, segundo dados do Banco do Nordeste. Devido a fatores como a falta de políticas públicas para a agricultura familiar, a concentração fundiária e o a gravamento dascond ições de produção dos a gric ultores em períod os de escassez de chuvas, tem havid o o impulsiona mento do crescimento dessa a tividade na região. Um dado releva nte a ser observado é a participação de homens na feitura da renda, uma vez que essa é uma atividade considerada de mulher. Neste artigo analisamos a atividade artesanal como uma fonte de renda, perpassa da por relações de gênero, atentando para a importância da renda renasc ença como ativida de de homem e de mulher e a sua feitura no cotidia no das mulheres, em que se entrelaçam trabalho, socialização de crianças e vivência lúdica.
\end{abstract}

Palavras-chave: artesanato; gênero; trabalho.

\section{Introdução}

Situado no Cariri paraibano, na Mesorregião da Borborema e Microrregião dos Carinis Velhos da Pa raíba (Carin Ocidental), o município de Camalaú possui 5.514 habitantes, sendo 2.743 homens e 2.771 mulheres. Destes, 2.357 pessoas residem na cidade e 3.157 na zona rural. Na cidade de Camalaú, as a tivida des econômica s bá sicas são o a rtesa na to, a agricultura familiar, a pecuária e o extrativismo rudimentar. O comércio e o setor de prestação de serviços são bastante modestos. O município não possui indústrias e sua maior fonte de renda advém do serviço público e das aposentadorias rura is. Ao lado de outros municípios - Congo, Monteiro, São João do Tigre, São Sebastião de Umbuzeiro e

Copyright $\odot 2006$ by Revista Estudos Feministas. 
Zabelê - Camalaú destaca-se pela produção da renda renascença, que se caracteriza porseruma renda de agulha, cujos pontos teriam tido origem na época do Renascimento.

Devido à importância da atividade da renda renascença para toda essa região e do ca rá ter distintivo que a mesma a tribui à vida da smulheres do lugar, este artigo a na lisa rá a atividade artesanal como uma fonte de rendimentos, perpassada por relações de gênero, a tentando para a importância da renda renascença como ativida de de homem e de mulher e a sua feitura no cotidiano das mulheres, em que se entrelaçam trabalho, socialização de crianças e vivência lúdica.

\section{A importância da renda como atividade de rendimentos}

A importância econômica da atividade da renda renascença na região do Carini paraibano pode ser observada, dentre outros aspectos, na quantidade de mulheres que trabalham na confecção da mesma. Em toda a região há cerca de qua tro mil mulheres que movimentam valores na ordem de $R \$ 200$ por mês. ${ }^{1}$ Com o desmonte da agricultura de subsistência, devido a fatores como a falta de políticas públicas para a agricultura familiar, a concentração fundiária e o agravamento das condições de reprodução dos agricultores por causa da escassez de chuvas, tem havido o impulsionamento do crescimento dessa atividade na região. Entre as atividades econômic as básicas do município encontram-se o extrativismo, o artesanato e a agropecuária rudimentar e de subsistência. As pessoas fazem carvão; tiram casca de angico; fabricam telhas e tijolos; fabricam cal; plantam milho e feijão; desenvolvem uma pequena agricultura inigada; criam cabras, porcos, ovelhas, vacas, entre outras atividades. Ultimamente tem havido, em toda a região do Cariri, um incentivo do govemo, via Banco do Nordeste, para a criação de cabras visando à produção de leite e derivados. 0 município de Camalaú é um dos mais pobres e subdesenvolvidos do Nordeste brasileiro, possuindo um índice de indigência de $91,1 \%{ }^{2}$

A a tividade artesanal da renda renascença passa a representar uma importante fonte de ingresso monetário para um grande número de famílias de a gricultores, ${ }^{3}$ situação que ta mbém ocorre em outros países da América La tina, como é o caso do México, que, "devido a o empobrecimento e a o caráter estacionário da produção a gríc ola, o artesa na to aparece como um recurso complementar apropriado, tendo se convertido, em alguns povoados, na principal fonte de rendimentos". ${ }^{4}$

\section{A renda como atividade de homem e de mulher}

A renda renascença também é produzida por homens. Há, no entanto, uma dific ulda de especial em tratar desse tema devido a o fa to de ser difícil conversar com um menino ou um rapaz rendeiro. Isso acontece porque há o temor de que seja posta em dúvida a sua masculinidade, caso eles admitam ou sejam vistos fazendo uma atividade considerada como eminentemente feminina. É fato comum na região estudada que há um grande número de homens, de várias idades, envolvidos na produção da renda renascença, principalmente nos sítios. Para ilustrar esse fa to, podemos destacar o caso de dois rapazes- Roberto ${ }^{5}$ e J osé, que possuem 25 e 20 a nos, respec tiva mente. 0 primeiro deles, Roberto, a prendeu a rendara os dez anos observando sua mã e tra balhar. Fez renda

\footnotetext{
${ }^{1}$ BANCO DO NORDESTE, 2000.

2 Dado do Conselho Regional de Economia da Paraíba.

${ }^{3}$ Segundo dados do PARAIWA, 1999.

${ }^{4}$ Nestor Garcia CANCLINI, 1983, p. 63.
} 
até os dezoito anos, porsera única forma de ajudara mãe, mas se escondia para que as pessoas não o vissem. Quando tirou os documentos e foi para São Paulo "tentara vida", nunca mais rendou, pois, segundo ele, fazer renda a trapalhava com as namoradas:

Fazer renda a trapalhava com as namorada. Namorei muito pouco. Fiz renda porque era o único meio de ganhar a vida. Eu ajudava mãe, comprava roupa e ia pra festas. [...] Trabalhava escondido. Quando chegava alguém me escondia.

O outro rapaz, José, é rendeiro e comerciante e ostenta uma atitude de orgulho com o fato de ser rendeiro. Com a toalha jogada sobre o ombro, me disse que havia trabalhado naquela peça, masque não havia feito sozinho, que "pagou alguns novelos". Enqua nto conversá va mos, a lg uns ra pazes, conhecidos de J osé, se a proxima ram e fic a ram dizendo brincadeiras. Talvez, entre minha 'a ceitação' com relação ao fato de ele rendar e as brincadeiras dos amigos, ele tenha preferido ficar do 'meu lado', chegando até a posarpara uma fotografia. Sua atitude foi bem diferente da de Roberto, fato que nos leva a considerar que o estarna feira vendendo a quela peça indic aria J osé como um rendeiro de poder aquisitivo maior que o de Roberto. Enquanto este apenas podia desmanchar novelos para terceiros, J osé pode comprar matéria-prima e também pagar para outras pessoas trabalharem para ele.

Essas diferenças incidem sobre a forma de lidarcom a renda. Se ser rendeiro é fa zer tra balho "de mulher", servendedorou comerciante é trabalho próprio "de homem". José é mais aceito entre os seus pares por também ser comerciante. Segundo um dos atravessadores do lugar, "fazer renda não é trabalho de homem não. Isso faz é espantar as mulheres". Essa atitude de discriminar o ato de tecer, também, é observada entre os homens do Vale do Jequitinhonha. Antes de os homens serem introduzidos na atividade, tinham a idéia de que, "se um homem tecer, ele vira mulher, as pemas vão afinar e o esperma vira á gua e ele não vai ter condições de sustentar a família". ${ }^{6}$

A idéia de renda como "trabalho de mulher" não é corroborada pelas mães rendeiras que, desde cedo, encaminham seus filhos nesse ofício. Por ocasião de uma visita à feira de Jataúba, acompanhamos a negociação entre uma rendeira e um comerciante. Tentando mantero preço pela peça - $\mathrm{R} \$ 250,00$ poruma toalha de banquete de 3 metros - a rendeira utilizou, como argumento mais forte, o fato de seu filho de nove anos ter trabalhado na confecção. Para ela, isso valorizava ma is a peça, tomava-a mais especial.

Motivo que leva as mães a ensinarem seus filhos homens, quando crianças, a atividade da renda renascença é o fa to de, no mundo rural, a socialização das crianças serealiza a través do trabalho. Logo cedo, em tomo dos cinco anos, meninos e meninas são iniciados no trabalho do roçado. Como a iniciação, na rena scença, também ocorre nesse período, e sendo a estia gem comum na região, os meninos acabam por a prender a rendar do mesmo modo como aprendem a trabalhar na roça. Essas duas atividades são constituintes da sua socializa ção. ${ }^{7}$

Nesse momento da infância, não há uma separação rígida entre trabalho feminino e trabalho masculino. É comum encontrar nos sítios crianças de ambos os sexos fazendo renda, pois essa é, em muitos casos, a única possibilidade de trabalho na maior parte do

\footnotetext{
${ }^{5}$ Qua nto a os nomes dos entrevistados, nos inspira mos na metodologia da História Oral, que, diferentemente, da Antropologia, mantém os nomes verdadeiros, pois entende que a pesquisa pode dar visibilidade às vozes de diversos sujeitos socia is.

${ }^{6}$ Maria Moraes SILVA, 1998, p. 97

7 Marilda de MENEZES, 2002 b.
} 
ano. Um caso emblemático é o de Maria Suelene, mulher de quarenta anos, rendeira há trinta. Segundo ela - que procura demonstrar que tem as rédeas da casa e da família nas mãos -, "todo mundo tem que trabalhar". Mã e de três filhos, duas meninas e um menino, Suelene diz, com firmeza, que logo cedo coloc ou os três para traba lharna renda. Quando questionada sobre o fato de ela haver ensinado o filho homem a rendar, ela respondeu que "todo mundo tem que trabalhar" e que "os filhos não devem fic arvagabundeando".

A narrativa da mãe mostra que o trabalho dos meninos e meninas, além de ser fonte de sobrevivência material para a família, também se fundamenta na transmissão de saberes e construção de profissões. Esse aspecto é ressaltado por vários autores que a nalisam o trabalho de crianças em famílias camponesas. Citamos, aqui, a análise de Neves, ${ }^{8}$ que faz referência ao trabalhadora rtesanal ou camponês, cujo uso da força de trabalho não responde diretamente à crescente expansão da a propria ção da ma is-valia e a o uso descartável do seu portador. A autora ressalta, ainda, que essas formas de uso do trabalho infantil antecedem e ultrapassam o sistema de produção capitalista, mas não eliminam, nec essa ria mente, as cond iç ões penosa s e prejudicia is a o desenvolvimento da criança ou do adolescente.

Tendo como base analític a o destaque dado pela a autora sobre os outros valores referenciais do trabalho de crianças em unidades camponesas, Menezes ${ }^{9}$ enfatiza a importância do trabalho na socialização de meninos e meninas. Nos termos da autora, essa socialização está "pautada por uma ética do trabalho que orienta a formação de homens e mulheres dignos (as) e honestos (as), capazes de serem respeitados (as) pela comunidade e de se reproduzirem a si próprios e às suas famílias".

Nesses termos, ao falar que "todo mundo tem que trabalhar", Suelene (40) faz referência a esse ethos que perpassa a visão da importância do trabalho na formação dos valores morais da família camponesa. 0 filho de Suelene aprendeu a rendarcom oito a nos. Atualmente, ele tem dezesseis a nose, há um a no, não fa z ma is renda. Tenta mos conversar rom ele, mas não tivemos sucesso. Segundo sua mãe, depois que foi c resc endo, fic ando rapazinho, "foi ficando besta, com vergonha de trabalhar na renda e não quer nem falar no assunto".

Essa postura é comum à maioria dos rapazes. Se, qua ndo crianças, eles trabalham sem se esconder, à medida que vão crescendo, não encontrando seus pares nessa atividade, passam a operar com a idéia de que rendar é "trabalho de mulher".

No conta to com as mulheres rendeira s de Ca ma laú, c ha mou-nos partic ula ratenção o fa to de elas nunca se referirem aos maridos como provedores do sustento da casa. De um modo geral, o trabalho da mulher é sempre tid o como ajuda. Socialmente espera-se que o homem seja provedor do sustento da família, atribuindo-se à mulher o papel de mãe e dona-de-casa. Mesmo quando a mulher exerce o papel de provedora do sustento familiar, a sua atividade laboral é considerada como subsidiária e complementar. Esse fato pode ser mais bem observado ao fazermos uma breve incursão na literatura que trata do trabalho da mulher.

Em um estudo realiza do sobre as labirinteiras da Chã dos Pereira, no município de Ingá, estado da Paraíba, foi observado que as mulheres, embora se percebendo como provedoras do sustento familiar, preferem atribuir a os maridos a condição de chefe-defamília e de provedor, demonstrando uma autodesvalorização do seu "papel". ${ }^{10}$

\footnotetext{
${ }^{8}$ Delma NEVES, 1999.

${ }_{9}$ MENEZ⿱ES, 2002b, p. 203; e 2002a.

${ }^{10}$ Regina GONÇALVES, 1996.
} 
Em um outro estud o realiza do sobre a renda de bilro, na llha de Santa Catarina/SC, a a utora observa, em suas entrevistas, que as rendeira s consideram sua atividade como complementar à dos ma ridos pesca dores. Em sua fala, uma das entrevista das demonstra que assumir um papel de relevância econômica só se justifica em situação de crise (doença, morte do marido), quando recai sobre a mulher o "papel" de manter financeiramente a família. ${ }^{11}$

Um estudo feito sobre o lugar da mulher em unidades domésticas camponesas a firma que o lugarocupado porcada membro da família está ligado à sua posição em relação às atividades que desenvolve no roçado ou na casa. As tarefas consideradas como tra ba lho são a quela s responsá veis pelo consumo fa milia re são rea liza da sno roça do, na unidade de produção. Já as tarefas correspondentes a ô âbito da casa são domésticas, e a casa é considerada como unidade de consumo. ${ }^{12}$

Em uma outra visão na qual a divisão sexual do trabalho é menos rígida, o trabalho é visto como atividade humana através da qual o homem, genericamente, garante a produção e reprodução da vida material e social. Todavia considera-se que, mesmo exercendo um trabalho igual ao dos homens, as mulheres não têm o mesmo esta tuto deles, visto que trabalho idêntic o não significa igualda de social entre homense mulheres. ${ }^{13}$

Segundo vá rios rela tos obtidos entre as rendeira s da região do Ca riri para ibano, a feitura da renda sempre esteve ligada à escassez, à falta de empregos, à pobreza. Na cidade de Camalaú a economia depende em parte da agricultura de subsistência (milho, feijão) e de um pequeno número de pescadores. Como já foi referido, é do emprego públic o e das a posenta dorias que advém a principal fonte de rendimentos. Assim, devido a esse conjunto de fatores, é que um grande número de mulheres passa a dependerdos poucos recursos obtidos com o seu trabalho na renda:

O leite de meus meninos saiu todinho daqui, da renda" (Gorete, 42 anos);

Criei três filhos com meu trabalho. Graças a Deus a té hoje tô puxando linha e vivendo a vida" (Zulmira, 56 a nos);

Com o pouco que eu ganho na renascença, eu sustento a casa. Meu marido é pedreiro, mas, a lém de nunca a rranjar serviço, todo dinheiro que ganha é pra beber" (Luciana, 36 anos).

Ouvind o os seus relatos e observando o seu cotidiano, vimos que muitas famílias acabam por ser sustentadas com a renascença. É nesse contexto que os filhos e filhas são criados a prendendo a a tribuir a o trabalho com a renda a sua sobrevivência. Pa rtindo dos discursos dessas mulheres e das observações de campo, consideramos importante ressa lta r c omo o sa ber-fazer dessa s rendeira s lhes confere distinção, qua nd o compara das a outra smulheresque, c omo elas, são a gric ultora se donas-de-casa, ma sque nã o possuem um outro saber que lhes dêem uma certa a utonomia no sustento da casa. Fazer renda permite a essas mulheres a condição de não ficarem na dependência absoluta de seus maridos ou companheiros. E meninas que ainda estão sendo iniciadas na renda renascença já associam seu aprendizado à independência financeira, como é o caso de Cacau, uma menina de 12 anos que acalenta o sonho de sercantora e gravarum CD.

Ao a na lisara renda como a tivid a de de mulher, algunsaspectos ga nha m relevância e revela m carac terístic a s que são consideradas próp ria s às rendeira s. Refiro-me a a tributos

\footnotetext{
${ }^{11}$ Andréa ZANELA, 1999.

12 Bea triz HERÉDIA, 1979.

${ }^{13}$ SILVA, 1998.
} 
como delicadeza, paciência, destreza com as mãos, qualida des nec essá ria s pa ra quem trabalha com linha e agulha e condições indispensá veis à feitura da renda.

Estudando uma ta refa eminentemente feminina, específic a do processo de traba lho da cana, o descarte (atividade que consiste no reconhecimento das doenças, classificação e recuperação da planta mediante a retirada das partes afetadas e da aplicação de agrotóxicos), Silva ${ }^{14}$ considera que, devido a sua natureza, o descarte é tido como trabalho feminino, pois "os qualificativos de um trabalho bem feito, leve, responsá vel, exigindo a ssiduida de e a tenção, estão rela ciona dos às mulheres. Porta nto, somente elas se mostram capazes de realizá-lo".

Guardadas as diferenças entre esse trabalho realizado no cultivo da cana e o trabalho com a renda, é possível encontrar elementos comuns como a atribuição de gênero que é dada a essa starefas, a o caracterizá-las como femininas. No caso da renda, como é um trabalho também realizado por homens, quando se trata da luta pela so brevivência, as a tribuições de gênero fic am fra giliza das. Nesses termos, na socia liza çã o de meninos e meninas de famílias camponesas, encontramos meninas/mulheres trabalhando na roça e meninos/homens trabalhando na renda.

É tecendo os pontos da renascença e entretecendo as suas vidas num misto de desmanchar novelos e desfazer os nós das dificuldades da vida que essas mulheres e c rianç a s constroem sua s vid a se seus sonhos. Alheia sà s disc ussões tra va das na a ca demia sobre o papel da mulher, muitas das rendeiras de Camalaú seguem suas vidas considerando que o sustento de suas casas provém do seu trabalho na renda.

Não queremos correr o risco de homogeneizar as "rendeiras de Camalaú" como sendo uma ca tegoria específic a e compa cta e, a partir daí, fa zer a firmações a pressa das. To da via, mesmo percebendo a varieda de das histórias de vida dessas mulheres, é possível considerar que há uma característic a comum que as identifica como um grupo social: o status que lhes é conferido pelo saber-fazer da renascença.

\section{Referências bibliográficas}

ALBUQUERQUE, Else de Farias. Desmanchando novelos e tecendo sonhos: a vida das rendeiras de Camalaú. 2002. Dissertação (Mestrado em Sociologia) - Programa de Pós-Graduação em Sociologia, Universidade Federal da Paraíba, Campina Grande.

BANCO DO NORDESTE. Diagnóstico das rendas do Cariri paraibano. 2000.

CANCLINI, Nestor Garcia. As culturas populares no capitalismo. São Paulo: Brasiliense, 1983.

GONÇ ALVES, Regina Célia. Vidas no labirinto: mulheres e trabalho artesanal: um estudo sobre as artesãs da Chã dos Pereira - Ingá/PB. 1996. Dissertação (Mestra do em Sociologia) - Centro de Humanidades, Universidade Federal da Paraíba, Campina Grande.

HERÉDIA, Beatriz Maria Alásia de. A morada da vida: trabalho de pequenos produtos do Nordeste do Brasil. Rio de Janeiro: Paz e Terra, 1979.

MENEZES, Marilda A. de. Redes e enredos nas trilhas dos migrantes: um estudo de família de camponeses. Rio de Janeiro: Relume Dumará; J oão Pessoa: Ed. Da UFPB, 2002a.

. "Memórias de infância de mulheres e homens camponeses". Trajetos. Revista e História UFC, v. 2, n. 3, p. 185-208, 2002b.

NEVES, Delma Pessanha. A perversão do trabalho infantil: lógicas socia is e alternativas de prevenção. Niterói: Intertexto, 1999.

${ }^{14}$ SILVA, 1999, p. 181. 
PARA'IWA - Coletivo de Assessoria e Documenta ção. Projeto Renda do Ca riri. J oão Pessoa, 1999.

SILVA, Maria A. Moraes. Fiandeiras, tecelãs, oleiras... Redesenhando as grotas e veredas. Projeto História, n. 16, p. 75-104, 1998.

. Errantes do fim do século. São Paulo: Ed. da UNESP, 1999.

ZANELLA, Andréa Vieira. "A renda que nem sempre gera renda". Revista de Ciências Humanas, Floria nópolis, n. 25, p. 133-150, 1999.

\section{The Material and Symbolic Value of Renaissance Lace}

Abstract: The municipality of Camalaú, in the Paraiban Cariri, is known for its production of renaissance lace. This activity is of great economic importance in the region, evidenced by, among other things, the quantity of women who work in the lace production. Data from the Banco do Nordeste (Northea stern Bank) report four thousand women dedic a ted simulta neously to family farming and crafts. Because of factors such as lack of public polic ies for family farms, land tenure concentration and the worsening of conditions for the reproduction of a griculture in drought periods, craft production has increased in the region. Observation shows that men have a relevant participation in lace production, even though it is considered a women's activity. This artic le examines craftwork as an inc ome source, wrought with mea nings from gender relations, emphasizing that the activity is of men and women whose daily activities link work, child socialization and play.

Key words: Handic rafts; Gender; Work. 